\title{
A Multi-concern Method for Identifying Business Services: A Situational Method Engineering Study
}

\author{
O. Ege Adali $\left.{ }^{\bigotimes}\right)$, Oktay Türetken, Baris Ozkan, Rick Gilsing, and Paul Grefen \\ Eindhoven University of Technology, De Zaale, 5612 AR Eindhoven, The Netherlands \\ \{o.e.adali, o.turetken, b.ozkan, r.a.m.gilsing, \\ p.w.p.j.grefen\} atue.nl
}

\begin{abstract}
Business services are offerings that enable organizations to achieve their strategic objectives by making their functionality accessible to their customers and business partners. Thus, organizations pay significant attention to and invest in the explicit identification and definition of their business services. This is, however, not a trivial endeavor as multiple concerns that are intrinsic to the concept of business service should be taken into consideration in identifying services. Existing business service identification methods used in isolation do not offer adequate coverage for these concerns. Addressing this issue, we propose a novel method assembled by situational method engineering from a set of existing service identification methods, taking the best aspects from each of them. In this paper, we present an instantiation of the situational method engineering approach alongside the details of the constructed method. We also provide a demonstration of the method with an illustrative scenario based on a real-life business case.
\end{abstract}

Keywords: Service identification $\cdot$ Method $\cdot$ Situational method engineering

\section{Introduction}

The most recent business approaches are increasingly shifting their focus away from goods-thinking to services-thinking [1]. Driven by the influence of digitalization, increased connectivity, and global economy, the concept of service has become central to value-creation [2]. As a result, many organizations are providing services as first-class standalone offerings in their value propositions, whereas many others are enhancing their offerings by transforming their products into services through servitization [3].

In this context, one major challenge for such organizations is the identification of their service offerings. When identifying service offerings, organizations have to deal with various service provisioning issues, such as determining what can be offered to which existing and potential customers and business partners [4-8], alignment of service offerings with the long-term strategic interests of the organization [9], and identification of business capabilities to provide a specific service offering [10-12]. To address this broad range of concerns, scholars have proposed the concept of 'business service', and relevant business service identification methods (BSIMs). 
The business service concept is a powerful abstraction that incorporates a number of design concerns to address service provisioning issues. At the meta-level, BSIMs provide procedures specifically designed to identify business services while addressing a number of these design concerns. BSIM procedures focus on a key business artifact (e.g., a business process, goal, business function, feature) and include a set of activities that employ this artifact in business service identification [13].

The literature reviews on BSIMs put forward a wide array of design concerns and investigate the BSIMs that they identified from various perspectives, each emphasizing a subset of such design concerns [13]. However, a thorough investigation of these reviews reveals that, while each BSIM addresses certain design concerns, a BSIM that is driven by a complete and refined set of reported design concerns is still lacking. Furthermore, existing BSIMs do not recognize contemporary perspective of markets reflected as the Service-Dominant (S-D) logic [2]. Therefore, a BSIM driven by both a complete and refined set of business service concerns and the contemporary business perspective can help organizations to identify business services that can enable them to better leverage this concept in addressing service provisioning issues.

In this paper we address this gap by developing a multi-concern business service identification method -MCBSIM- that covers a wider and more comprehensive selection of business service design concerns. In developing the MCBSIM, we followed the situational method engineering (SME) approach as it enables the construction of a method by assembling existing and reusable method fragments stored in a method base $[14,15]$. In this regard, first, we have defined requirements for the MCBSIM based on the concerns related to business services and identified and analyzed 47 existing BSIMs to investigate the extent to which they meet these requirements. Next, we have identified and integrated carefully selected parts of a number of BISMs into a coherent method that meets the requirements set-forth. This paper presents the MCBSIM and demonstrates it by going through a real-life business scenario.

The rest of this paper is organized as follows: Sect. 2 introduces the related work on business services and BSIMs. Section 3 presents the research design for the development of the MCBSIM. We describe the MCBSIM and demonstrate its use in the business case in Sects. 4 and 5, respectively. Finally, Sect. 6 concludes with limitations and future research directions.

\section{Background and Related Work}

In this section, we first provide related work on business services and concerns related to the concept of business service and then, on BSIMs and their shortcomings.

\subsection{Business Services}

Business services are engineering artifacts designed by service providers with the purpose of achieving their strategic goals [4-6]. In that sense, the design of a business service involves bringing specificity to resources which have the potential to be acquired by specific customers or customer segments [16]. All in all, business services represent different types of value propositions in the form of offerings that service providers 
expose to advertise and manage their resources and interactive processes [11]. As is the case with the parent term service, the literature provides many different definitions of the term business service. Each definition caters to a set of design concerns intrinsic to the context in which the term is used. As a result, this creates an ambiguity surrounding the term and this ambiguity represents a challenge to the investigation of how business services are identified and defined. Therefore, as a first step in the purpose of designing a BSIM, we have studied the definitions of the concept of business service in the scholarly literature. These definitions bring together various design concerns related to the concept.

To discover these associated design concerns -which we will refer to as business service concerns from this point on-, we conducted a literature review by performing searches on established scientific databases (Ebsco, ScienceDirect, Scopus SpringerLink, Web of Science, and Wiley) using the search string "business service". This resulted in an initial set of 104 studies. Next, we applied backward snowballing on these studies [17]. The main inclusion criterion for selecting studies from the start set was that the study should propose a definition for the term 'business service'. We conducted two iterations and our final list of studies included a total of 16 studies. The references of these studies can be found in Table 1 below. We extracted each definition introduced by the aforementioned 16 studies and applied a grounded theory approach [18] to extract and refine a complete set of business service concerns. Accordingly, we first coded the business service concerns that each definition adheres to and then translated these into overarching themes by applying axial coding [19]. The resulting themes with the sources of definitions is presented in Table 1.

Table 1. Business service concerns

\begin{tabular}{l|l|l}
\hline$\#$ & Business service concern & Source(s) \\
\hline C1 & A business service is connected to business goals and objectives & {$[4,20-24]$} \\
\hline C2 & A business service offers a business capability & {$[4-7,10,11,25]$} \\
\hline C3 & $\begin{array}{l}\text { A business service encapsulates combinations of basic intangible and } \\
\text { tangible resources }\end{array}$ & {$[6,7,26]$} \\
\hline C4 & A business service is customer-facing - external & {$[4-8,27]$} \\
\hline C5 & A business service is composed of infrastructure services & {$[5,7]$} \\
\hline C6 & $\begin{array}{l}\text { A business service has a well-defined interface that explicates to the } \\
\text { service customer how to interact with the business service }\end{array}$ & {$[25,26]$} \\
\hline C7 & A business service has mechanisms that realize its delivery & {$[7]$} \\
\hline C8 & A business service shall have a service owner & {$[4-7,25]$} \\
\hline C9 & A business service is connected to one or more value propositions & {$[7,22]$} \\
\hline C10 & $\begin{array}{l}\text { A business service's temporal and logical dependencies to other } \\
\text { business services is explicitly defined }\end{array}$ & {$[5,7,28]$} \\
\hline C11 & $\begin{array}{l}\text { All the information regarding a business service is stored in a service } \\
\text { catalogue }\end{array}$ & {$[9,29]$} \\
\hline
\end{tabular}




\subsection{Business Service Identification Methods (BSIMs)}

The aim of Business service identification is to identify and define candidate business services on the basis of business service concept [9]. Since the concept of business service involves multiple concerns, service identification involves the consideration of these concerns as well. This requires a systematic method that supports the examination of organizations from multiple perspectives [13]. In order to address this need, scholars and practitioners proposed several BSIMs. These methods use different techniques that involve procedures focusing on a key business artifact (e.g., business processes, goals, business functions, features) and a set of activities that employ this artifact in identifying business services [13]. However, reviews conducted on these BSIMs conclude that, while BSIMs recognize the business service concerns to a certain degree, there is no consensus on how to deal with multiple business service concerns in a systematic way [13]. Comparing the previous work on BSIMs, we identified 47 unique BSIMs ${ }^{1}$ which populate our method base.

\section{Research Design}

In the development of MCBSIM, we employed an SME approach [14, 30]. Accordingly, every SME process includes two main tasks: setting the method engineering goal and constructing a method that meets this goal [14]. Below we elaborate on each task.

\subsection{Setting the Method Engineering Goal}

Aligned with the most contemporary perspective to marketing S-D logic [2] we define the context of our project as "identification of business services for a service provider making a value proposition to a business network to co-create value with other actors in the same network". Furthermore, the service provider's major concern is to leverage the business service concept to the fullest in terms of addressing 11 business service concerns. In the light of this context information, an analysis of our method base revealed that the present methods provided method chunks to perform certain aspects of business service identification aligned with our context such as consideration of network or value propositions during identification. Additionally, we observed the existence of at least one method that adheres to a specific business service concern. Therefore, we decided to follow a method driven strategy and set our method engineering goal as "assembling a new method by re-using the method chunks of existing BSIMs".

\subsection{Construction of the Method}

In line with our goal, we followed an assembly-based method engineering strategy described in [30]. The process for this strategy consists of three steps: specification of method requirements, selection of method chunks, and assembly of method chunks. Below we elaborate on each step.

\footnotetext{
${ }^{1}$ Please visit the following link for the method base: https://sites.google.com/view/bsimbase/.
} 


\section{Specification of Method Requirements}

For this stage we followed the process driven strategy as our goal was to construct a new method [30]. Accordingly, we first determined our method engineering intentions (MEIs) as shown in Table 2. These intentions were directly elicited from the characteristics of the method context described in Sect. 3.1.

Table 2. Method engineering intentions

\begin{tabular}{l|l}
\hline$\#$ & Method intention \\
\hline MEI1 & $\begin{array}{l}\text { The method should identify business service(s) that comply with } 11 \text { business service } \\
\text { concerns }\end{array}$ \\
\hline MEI2 & The method should target a focal business unit (FBU) to specify business service(s) \\
\hline MEI3 & The method should identify business services based on a value proposition of the FBU \\
\hline MEI4 & $\begin{array}{l}\text { The method should be applied in a business network consisting of actors defined in the } \\
\text { value proposition }\end{array}$ \\
\hline
\end{tabular}

To realize our MEIs, we developed a strategy driven requirements map (Fig. 1) as described in [30]. This map was based on the most comprehensive BSIM [31] in our method base. Each meta-step (MS) of the map and the business service concern it complies with are shown in Fig. 1 as well. The meta-steps MS3 and MS5 were already present in the BSIM and were directly carried over to the map. To comply with C9, we added MS1 which simply involves selecting a value proposition. Furthermore, we added MS2 to comply with C4 and C8 and MS4 to comply with C1 and C10. The arrows in the map represent strategies, each satisfying the objective of the MS connected to the arrowheads. Accordingly, the initial strategy: "Value proposition driven strategy" simply involves selecting a value proposition and the terminating strategy "Completeness strategy" involves identification of all business services for the selected value proposition. The remaining strategies (S1-4) represent placeholders for specific method chunks. What S1-S4 entail and how method chunks were selected for them are explained in the next step.

\section{Selection of Method Chunks}

As indicated in Fig. 1, our method selection was targeted at finding suitable method chunks for strategies S1-4. For selecting the chunks, we extensively used the MEIs and based on them we developed the following queries for each strategy:

- S1: Application domain $=$ 'Information Systems' \& Design activity $=$ 'Model the Value Co-Creation Context' \& Situation = 'Business Services' \& Intention = 'Identify goal dependencies between actors'

- S2: Application domain = 'Information Systems' \& Design activity = 'Capture the Core Business' \& Situation = 'Business Services' \& Intention = 'Map business capabilities of the focal business unit'

- S3: Application domain = 'Information Systems' \& Design activity = 'Relate the Core Business to the Value Creation Context' \& Situation $=$ 'Business Services' \& 


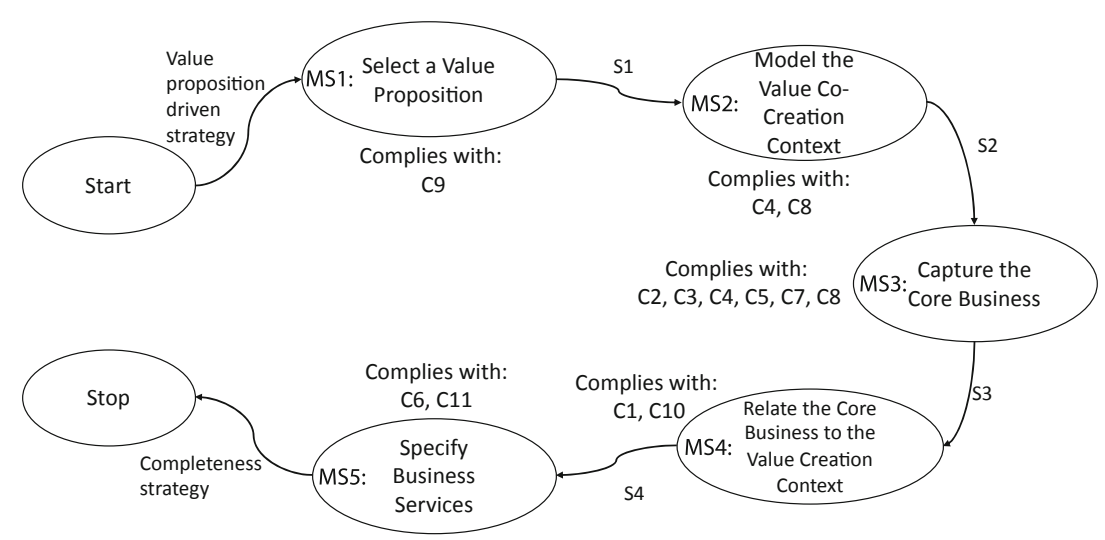

Fig. 1. The requirements map

Intention = 'Map business capabilities of the focal business unit to goals of the value creation actors'

- S4: Application domain = 'Information Systems' \& Design activity = 'Design Service Specifications' \& Situation $=$ 'Business Services' $\&$ Intention $=$ 'Create service specifications'

Each BSIM residing in our method base is labeled with specific tags indicating its domains, design activity, situation and intention. Therefore, we utilized these tags for querying the method chunks meeting the requirements of each strategy. Our queries resulted in selection of a total of 13 method chunks (MCs). The resulting set of MCs for each query is given in Table 3.

\section{Assembly of Method Chunks}

We followed the association strategy at this stage as our selected method chunks each corresponded to a different functionality [30]. Accordingly, we looked for method chunks which can be bridged together through their input and output products. This means, the output product of the first chunk in line should be the input product of the following chunk and so on. The input and output products of each method chunk are given in Table 3. Apart from the match between input and output products the assembled set of methods should also comply with all of the strategies S1-4.

In terms of complying with strategies, S3 demands MC3: Capability Modeling method chunk. Considering the fact that MC3 is a must-have method chunk, the method chunks that are both covering S1 and compatible with MC3 are MC1: $i$ * Strategic Dependency Modelling and MC11: Goal and Scenario Modelling. In terms of covering S1 and being compatible with MC3, MC8: Business Service Specification stands out from the crowd as the only option (as MC2: P2S' input product does not match with MC3's output product). Overall, our final assembly consists of method chunks MC1, MC3 and MC8 and explained in the next section. 
Table 3. Selected method chunks

\begin{tabular}{|c|c|c|c|c|c|c|c|}
\hline MC \# & Method chunk & Input & Output & S1 & $\mathrm{S} 2$ & S3 & S4 \\
\hline $\mathrm{MC1}$ & $\begin{array}{l}\text { i* Strategic } \\
\text { Dependency } \\
\text { Modelling [32-35] }\end{array}$ & $\begin{array}{l}\text { Stakeholders and } \\
\text { Their Objectives }\end{array}$ & $\begin{array}{l}\text { Goal Model } \\
\text { including Goals and } \\
\text { Means (Tasks) }\end{array}$ & $\mathrm{x}$ & $\mathrm{x}$ & & \\
\hline $\mathrm{MC} 2$ & $\begin{array}{l}\text { P2S (from process to } \\
\text { services) [36] }\end{array}$ & $\begin{array}{l}\text { Business Process } \\
\text { Models }\end{array}$ & $\begin{array}{l}\text { Service } \\
\text { Specifications }\end{array}$ & & & & $\mathrm{x}$ \\
\hline MC3 & $\begin{array}{l}\text { Capability Modeling } \\
{[31,35]}\end{array}$ & Business Tasks & $\begin{array}{l}\text { Capability } \\
\text { Model/Map }\end{array}$ & & $\mathrm{x}$ & $\mathrm{x}$ & \\
\hline MC4 & $\begin{array}{l}\text { Enterprise Business } \\
\text { Modeling (Input } \\
\text { Process and Entity } \\
\text { Models) [37] }\end{array}$ & $\begin{array}{l}\text { Business Process } \\
\text { Models }\end{array}$ & $\begin{array}{l}\text { Service Model } \\
\text { (Object diagram) }\end{array}$ & $\mathrm{x}$ & $\mathrm{x}$ & & \\
\hline MC5 & $\begin{array}{l}\text { Intention - Strategy } \\
\text { Map [38] }\end{array}$ & Business Goals & $\begin{array}{l}\text { Intention - Strategy } \\
\text { Model }\end{array}$ & $\mathrm{x}$ & & & \\
\hline MC6 & $\begin{array}{l}\text { Business Process } \\
\text { Decomposition with } \\
\text { Activity clustering } \\
{[39]}\end{array}$ & Business Use Cases & Activity Clusters & & $\mathrm{x}$ & & \\
\hline MC7 & $\begin{array}{l}\text { Functional } \\
\text { Decomposition with } \\
\text { Visibility and } \\
\text { Takeover [40] }\end{array}$ & $\begin{array}{l}\text { Business Process } \\
\text { Models }\end{array}$ & $\begin{array}{l}\text { Activity Clusters } \\
\text { with Associated } \\
\text { Actors }\end{array}$ & $\mathrm{x}$ & $\mathrm{x}$ & & \\
\hline MC8 & $\begin{array}{l}\text { Business Service } \\
\text { specification [31] }\end{array}$ & $\begin{array}{l}\text { Capability } \\
\text { Model/Map }\end{array}$ & $\begin{array}{l}\text { Business Service } \\
\text { Specification }\end{array}$ & & & & $\mathrm{x}$ \\
\hline MC9 & $\begin{array}{l}\text { Enterprise modeling } \\
\text { with financial } \\
\text { network modeling } \\
{[41]}\end{array}$ & $\begin{array}{l}\text { Business Process } \\
\text { Models }\end{array}$ & Activity Clusters & $\mathrm{x}$ & $\mathrm{x}$ & & \\
\hline MC10 & $\begin{array}{l}\text { Feature and Feature } \\
\text { Binding analyses [42] }\end{array}$ & Features & Feature Model & & $\mathrm{x}$ & & \\
\hline MC11 & $\begin{array}{l}\text { Goal and Scenario } \\
\text { Methodology [43, } \\
44]\end{array}$ & Business Goals & Goal and Task Model & $\mathrm{x}$ & & & \\
\hline $\mathrm{MC} 12$ & $\begin{array}{l}\text { A Service Model } \\
\text { Design Based on Use } \\
\text { Case [45] }\end{array}$ & Business Use Cases & Activity Clusters & & $\mathrm{x}$ & & \\
\hline MC13 & $\begin{array}{l}\text { Inter-Enterprise } \\
\text { Business Process } \\
\text { Modeling [46] }\end{array}$ & $\begin{array}{l}\text { Business Process } \\
\text { Models }\end{array}$ & $\begin{array}{l}\text { Inter- Enterprise } \\
\text { Business Process } \\
\text { Models }\end{array}$ & $\mathrm{x}$ & & & \\
\hline
\end{tabular}




\section{MCBSIM}

The method, which consists of four main steps as presented in Fig. 2, has been designed to be used in a context where a focal business unit (FBU) makes a value proposition to co-create value with the actors (including customers and other stakeholders) in a certain context. Accordingly, the initial input for the method is a value proposition that the FBU aims to make in a certain value co-creation context.

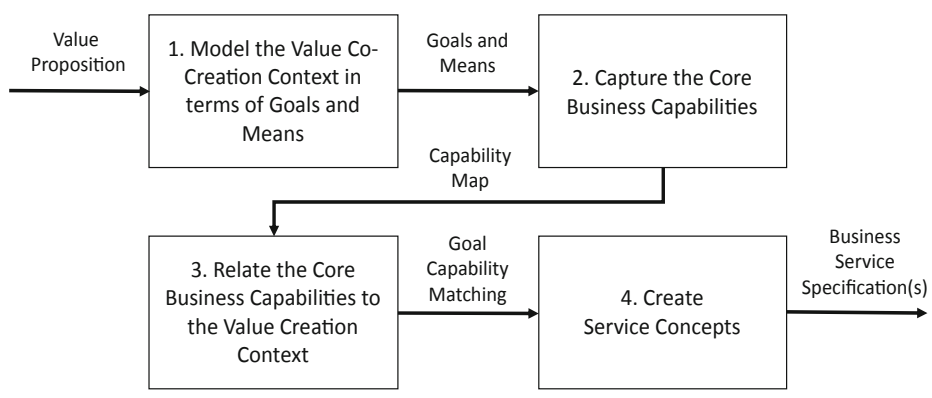

Fig. 2. MCBSIM

In Step 1, the objective is to model the value co-creation context in terms of determining goals and means dependencies between the value co-creation actors. The chosen method chunk for carrying out this step MC1: $i^{*}$ Strategic Dependency Model [47] that supports four main modelling concepts:

- Actor: A business role (e.g., organization and customer) that carries out actions to achieve goals by exercising its knowhow. We refer to an actor as a Value Co-creation Actor in this body of work.

- Goal: A desirable business state an actor aims to reach or sustain.

- Means: A concrete course of action (task) taken to accomplish goals. The realization of a means is under the control of the actor who proposes (owns) the means.

- Dependency: A link between two actors indicating that one actor (depender) depends on the other (dependee) for something in order that the former may attain some goal. Two types of dependencies are considered:

- Goal Dependency: The depender depends on the dependee to bring about a certain state in the world. The dependee is given the freedom to choose how to do it.

- Means or Task-dependency: The depender depends on the dependee to carry out an activity. A task dependency specifies how the task is to be performed, but not why.

The output of this step is a set of goal models: a generic model of the whole context, and goal models focusing on one-to-one goals and means dependencies between the FBU and each party in the context. It should be noted that the goal models are relative to the value co-creation context.

In Step 2, the main objective is to focus on the FBU and determine the business capabilities of the FBU, which contribute in making the selected value proposition. 
Various definitions of capabilities exist in the literature [48], however, we adopted the definition provided in [49] as it is a synthesis of the definitions provided in the literature. Accordingly, a capability (1) is possessed by a resource or resource groups of resources (tangible and intangible), (2) is the potential for action via a process, and (3) produces a value for a customer (internal/external).

To capture such capabilities, we used the template given in Fig. 5 which was adapted from [49]. The method chunk for carrying out this step MC8: Capability Modeling [31] captures capabilities by defining service domains and identifying capabilities that exist in a specific service domain [31]. A service domain is described as a sphere of control that contains a collection of service operations to achieve related goals [31]. The service operations are the activities that are carried out within the service domain to interact with other service domains [50].

In Step 3, the main objective is to determine the capabilities that enable the achievement of identified goals and means. As described in MC8: Capability Modeling [31], the focus of the determination activity is to match the delivered business outcome of each capability with one or more goals and processes (or activities in the processes) to the means. After the matching, the capabilities that are necessary to make the value proposition are identified. These capabilities are the main output of this stage.

In Step 4, the achieved outputs are combined and processed for specification of the business services as described in MC8: Business Service Specification [31]. For specification, we used the template given in Fig. 7 which was designed in accordance with 11 business service concerns. As depicted in template, a business service specification involves a set of business service attributes, such as the capability, owner, service operations, used resources, etc.

\section{Demonstration}

In this section, we demonstrate the utility of our method by applying it in an illustrative scenario that is based on a real-life business case. The scenario depicts the case for a new urban bike sharing business model. We omit the names of the organizations in the scenario to keep their anonymity. In the selected business model, there are four actors: traveler (e.g., tourists, students, employees), bike sharing service provider, bike maintenance provider, and the local municipality. The co-created value proposed for the traveler is flexible and comfortable travelling experience via cycling around the city. Thus, the value to be co-created with the business model encapsulates high availability and widespread coverage of bicycles within the city. This should allow traveler, whenever s/he desires, to take a bicycle and travel around the city. The traveler is not concerned with managing or maintaining the bicycle and can store the bicycle at any available slot at a parking station. As such, flexibility and comfort should be granted to the travelers. How each actor contributes to the value co-creation is described below:

Traveler-being the customer-contributes to the value co-creation through providing data on the usage of the service. Therefore, the value proposition of the traveler is profile data and data about service-use. Bike Sharing Service Provider contributes to the value co-creation by providing the facilities for bike sharing. As such, it is responsible for establishing the infrastructure for the bicycles, the software system to operate 
and use the bicycles, as well as the IT system to interact with users. Bike Sharing Service Provider is the focal business unit (FBU) of the business case. Bike Maintenance Provider contributes to the value co-creation by ensuring that bikes are in good conditions and available for travelers wherever and whenever they desire. Local Municipality contributes to the value co-creation by providing either the legal, financial or operational support.

In step 1, we regarded the value co-creation contribution of each actor (except the customer) as that actor's motivations and interests [47] and iteratively dissected these contributions into goals and means. On the other hand, the goal(s) and the single mean of the customer were defined by dissecting the main characteristic of the co-created value which is flexible travel. For space considerations, we only provide the goal model (Fig. 3) that depicts the goals and means dependencies between the FBU (service provider) and customer (traveler).

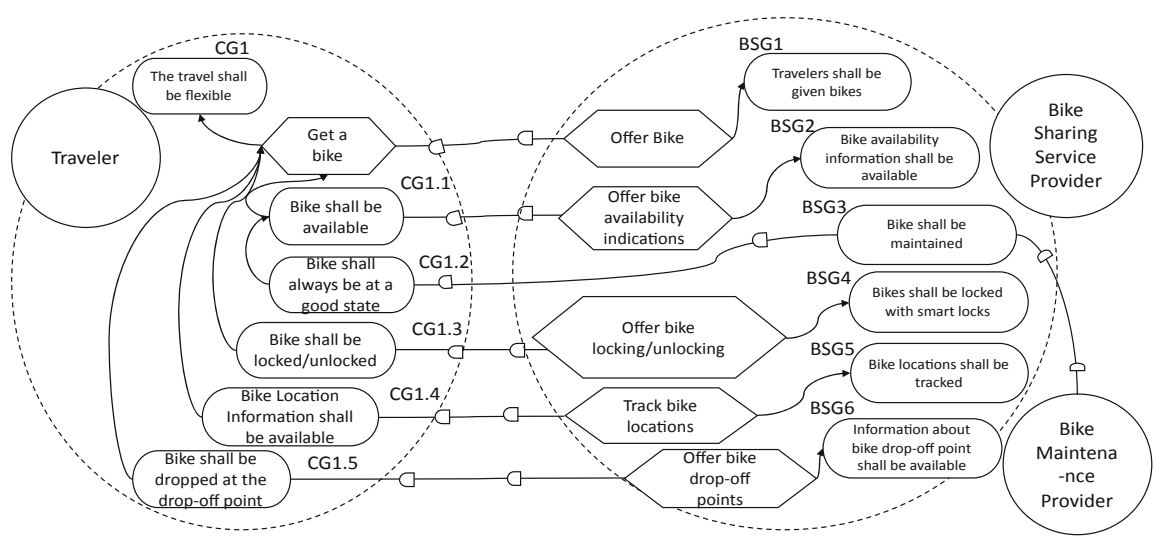

Fig. 3. i* goal model for value co-creation context (between service provider and traveler)

In step 2, we determined the service domains and service operations of the FBU based on the means of the FBU defined in goal models. Then, we matched these service operations to an already existing list of business capabilities of the FBU which are shown in Fig. 4. Furthermore, we re-defined each capability in detail according to our template. Figure 5 presents an example that depicts a specification for the capability "bike lending".

In step 3, we explicitly linked the capabilities that enable the FBU to achieve the goals defined in Step 1. Then, we examined the linked capabilities against 11 business service concerns to identify capabilities that can be business service candidates. This resulted in selection of the set of capabilities: Bike Lending and Traveler Guidance (as depicted in Fig. 6). The capability: Service Platform Management is an enabling capability for the other capabilities, and it is not provided to the value co-creation context (i.e. does not comply with concern C4), therefore, is not a candidate business service. Furthermore, the capabilities Bike Maintenance and Accident Handling are partner capabilities that do not belong to the FBU. 


\begin{tabular}{|c|c|c|}
\hline & Service Operations & Capabilities \\
\hline \multirow[t]{2}{*}{ Bike Pick-up } & Unlock Bike & \multirow[b]{2}{*}{ Bike Lending } \\
\hline & Start Session & \\
\hline \multirow[t]{3}{*}{ Bike Commute } & Track Travel & \\
\hline & Handle Bike Failure & Bike Maintenance \\
\hline & Handle Accident & 8 Accident Handling \\
\hline \multirow[t]{2}{*}{ Bike Drop-off } & Lock Bike & \multirow{2}{*}{ Bike Lending } \\
\hline & End Session & \\
\hline \multirow[t]{2}{*}{ Traveler Guidance } & Suggest Station & \multirow{2}{*}{ 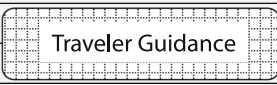 } \\
\hline & Share Avail. Information & \\
\hline Bike Availability & Maintain Bikes (Predictive) & Bike Maintenance \\
\hline \multirow[t]{4}{*}{ Platform Management } & Manage Data & \multirow{4}{*}{$\begin{array}{l}\text { Service Platform } \\
\text { Management }\end{array}$} \\
\hline & Secure Platform & \\
\hline & Analyze Data & \\
\hline & Provide Analytics & \\
\hline
\end{tabular}

Fig. 4. Service domains and business capabilities

\begin{tabular}{|l|l|l|}
\hline Business Capability: & Primary Capability 1: Bike Lending \\
\hline Business Purpose: & Enable travelers to get bikes. \\
\hline Capability Type: & Primary Capability \\
\hline Capability Owner: & Bike Sharing Service Provider \\
\hline Strategic Goals Addressed: & $\begin{array}{l}\text { Travelers shall be given bikes } \\
\text { Bikes shall be locked with smart locks } \\
\text { Bike locations shall be tracked }\end{array}$ \\
\hline Dependencies to Other Capabilities: & Enabling Capability: Service Platform Management \\
\hline Process & Tangible Resources & Intangible Resources \\
\hline Unlock Bike & Bike Lock, Bike & Mobile App \\
\hline Start Session & Bike, Bike Station & Mobile App \\
\hline Track Commute & Bike & Mobile App \\
\hline Lock Bike & Bike Lock, Bike & \\
\hline End Session & Bike, Bike Station & \\
\hline
\end{tabular}

Fig. 5. Business capability specification for bike lending

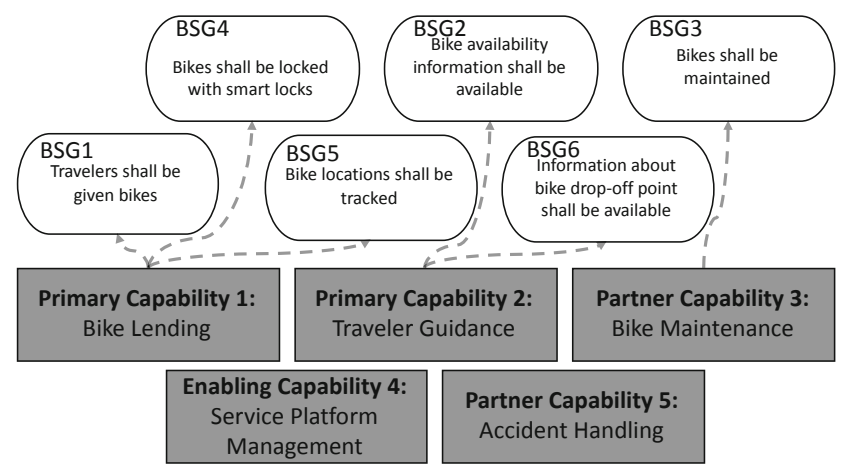

Fig. 6. Relationship between capabilities and goals 
In step 4, we specified two business services for 2 FBU capabilities: Bike Lending and Traveler Guidance by bringing together all the entities and properties of a business service as defined by our 11 business service concerns. A specification for the Bike Lending business service is presented in Fig. 7.

\begin{tabular}{|l|l|}
\hline Business Service: & Bike Lending Service \\
\hline Connected Value Proposition: & Flexible Urban Travel via Bike \\
\hline Connected Business Capability: & Bike Lending \\
\hline Customer Goals Addressed: & The travel shall be flexible \\
\hline \multirow{2}{*}{ Strategic Goals Addressed: } & $\begin{array}{l}\text { Travelers shall be given bikes } \\
\text { Bikes shall be locked with smart locks } \\
\text { Bike locations shall be tracked }\end{array}$ \\
\hline Business Service Owner: & Bike Sharing Service Provider \\
\hline & $\begin{array}{l}\text { Unlock Bike } \\
\text { Start Session } \\
\text { Track Travel } \\
\text { Business Service Operations: } \\
\text { Lock Bike } \\
\text { End Session }\end{array}$ \\
\hline \multirow{2}{*}{ Related Processes: } & $\begin{array}{l}\text { Unlock Bike } \\
\text { Start Session } \\
\text { Track Travel } \\
\text { Lock Bike } \\
\text { End Session }\end{array}$ \\
\hline Used Resources: & Bike Lock, Bike, Bike Station, Mobile App \\
\hline Required Business Services: & Traveler Guidance, Bike Maintenance, Accident Handling \\
\hline
\end{tabular}

Fig. 7. Business service specification for bike lending

\section{Conclusion, Limitations and Future Work}

In this paper, we present a method for the identification of business services. The main objective of the proposed method is to cover the concerns that relate to the design of business services during their identification. To achieve this objective, we identified the business service concerns and followed an SME approach to develop the method. In terms of the followed SME approach, we transformed business service concerns into method building objectives, identified method chunks realizing these objectives from a method-base of 47 methods, and assembled the identified method chunks into a procedural method. Furthermore, we demonstrated the method with an illustrative scenario based on a real-life business case.

Business service concept is a powerful abstraction to determine the service offerings of organizations. However, fully leveraging this abstraction requires recognition of the concerns affiliated with it. In comparison, the proposed method recognizes and leverages the business service concept better than previously proposed methods. It yields business services that are true to their intended form and purpose by building on carefully selected method chunks each adhering to a specific concern affiliated to the business service concept. Furthermore, previously proposed methods are disconnected from the contemporary perspective of markets that is conceptualized as the Service-Dominant (S-D) logic [2]. The proposed method takes the central theme of S-D logic-value co-creation- as its context to better align with the views of modern business. 
This study is subject to potential limitations mainly due to the strategy used to demonstrate the utility of the proposed method. A demonstration with an illustrative scenario is usually tailored to an ideal context and thus, is highly prone to hinder the discovery of issues that might result from the use of the artifact at hand in a real setting or context [51]. Since the proposed method and particularly its steps are highly rooted in academic literature - mainly in the form of business service concerns and existing BSIMs-, its effects on a real-world situation are yet to be discovered. Therefore, as future work, the method can be applied in a number of real-life scenarios in the form of case studies, and its utility and validity can be further evaluated using qualitative research methods that involve the practitioners as users of the method. Accordingly, the method can be improved and finetuned to address any potential shortcomings discovered in these evaluations.

\section{References}

1. Plugge, A., Janssen, M.: Exploring determinants influencing a service-oriented enterprise strategy: an executive management view BT - digital services and platforms. Considerations for Sourcing, pp. 35-55 (2019)

2. Vargo, S.L., Lusch, R.F.: Evolving to a new dominant logic for marketing. J. Mark. 68(1), 1-17 (2004)

3. Wolfson, A., Dominguez-Ramos, A., Irabien, A.: From goods to services: the life cycle assessment perspective. J. Serv. Sci. Res. 11(1), 17-45 (2019)

4. Cherbakov, L., Galambos, G., Harishankar, R., Kalyana, S., Rackham, G.: Impact of service orientation at the business level. IBM Syst. J. 44(4), 653-668 (2005)

5. Sanz, J., Nayak, N., Becker, V.: Business services as a modeling approach for smart business networks (2006)

6. Tohidi, H.: Modelling of business services in service oriented enterprises. Procedia Comput. Sci. 3, 1147-1156 (2011)

7. Flaxer, D., Nigam, A.: Realizing business components, business operations and business services. In: IEEE International Conference on E-Commerce Technology for Dynamic EBusiness, pp. 328-332 (2004)

8. Brocke, H., Uebernickel, F., Brenner, W.: A methodical procedure for designing consumer oriented on-demand IT service propositions. Inf. Syst. E-bus. Manag. 9(2), 283-302 (2011)

9. Arsanjani, A., Ghosh, S., Allam, A., Abdollah, T., Ganapathy, S., Holley, K.: SOMA: a method for developing service-oriented solutions. IBM Syst. J. 47(3), 377-396 (2008)

10. Lusch, R.F., Nambisan, S.: Service innovation in the digital age service innovation: a servicedominant logic perspective. MIS Q. 39(1), 155-176 (2015)

11. Turetken, O., Grefen, P., Gilsing, R., Adali, O.E.: Service-dominant business model design for digital innovation in smart mobility. Bus. Inf. Syst. Eng. 61(1), 9-29 (2019)

12. Suratno, B., Ozkan, B., Turetken, O., Grefen, P.: A method for operationalizing servicedominant business models into conceptual process models. In: Shishkov, B. (ed.) BMSD 2018. LNBIP, vol. 319, pp. 133-148. Springer, Heidelberg (2018). https://doi.org/10.1007/ 978-3-319-94214-8_9

13. Huergo, R.S., Pires, P.F., Delicato, F.C., Costa, B., Cavalcante, E., Batista, T.: A systematic survey of service identification methods. Serv. Oriented Comput. Appl. 8(3), 199-219 (2014)

14. Ralyte, J., Deneckere, R., Rolland, C.: Towards a generic model for situational method engineering. In: Eder, J., Missikoff, M. (eds.) CAiSE 2003. LNCS, vol. 2681, pp. 95-110. Springer, Heidelberg (2003). https://doi.org/10.1007/3-540-45017-3_9 
15. Iacovelli, A., Souveyet, C., Rolland, C.: Method as a Service (MaaS). In: 2008 Second International Conference on Research Challenges in Information Science, pp. 371-380 (2008)

16. Arnould, E.J.: Service-dominant logic and resource theory. J. Acad. Mark. Sci. 36(1), 21-24 (2008)

17. Wohlin, C.: Guidelines for snowballing in systematic literature studies and a replication in software engineering. In: Proceedings of the 18th International Conference on Evaluation and Assessment in Software Engineering, pp. 38:1-38:10 (2014)

18. Corbin, J., Strauss, A.: Basics of Qualitative Research: Techniques and Procedures for Developing Grounded Theory, 3rd edn. Thousand Oaks, California (2008)

19. Charmaz, K.: The search for meanings - grounded theory. In: Rethinking Methods in Psychology, pp. 27-49. Sage Publications, London (1996)

20. Estrada, H.: A service-oriented approach for the $i^{*}$ framework. Universidad Politecnica de Valencia (2008)

21. Flaxer, D., Nigam, A., Vergo, J.: Using component business modeling to facilitate business enterprise architecture and business services at the US Department of Defense. In: IEEE International Conference on e-Business Engineering (ICEBE 2005), pp. 755-760 (2005)

22. Nayak, N., Nigam, A., Sanz, J., Marston, D., Flaxer, D.: Concepts for service-oriented business thinking. In: Proceedings - 2006 IEEE International Conference on Services Computing, SCC 2006, pp. 357-364 (2006)

23. Tians, C., Ding, W., Cao, R., Lee, J.: Business componentization: a guidance to application service design. In: Min Tjoa, A., Xu, L., Chaudhry, S.S. (eds.) Research and Practical Issues of Enterprise Information Systems, pp. 97-107. Springer US, Boston (2006). https://doi.org/ 10.1007/0-387-34456-x_10

24. Sanz, J., et al.: Business services and business componentization: new gaps between business and IT. In: IEEE International Conference on Service-Oriented Computing and Applications (SOCA 2007), pp. 271-278 (2007)

25. Estrada, H., Martínez, A., Santilí An, L.C., Erez, J.: A new service-based approach for enterprise modeling (2013)

26. Karakostas, B., Zorgios, Y., Alevizos, C.C.: The semantics of business service orchestration. In: Eder, J., Dustdar, S. (eds.) BPM 2006. LNCS, vol. 4103, pp. 435-446. Springer, Heidelberg (2006). https://doi.org/10.1007/11837862_41

27. Cartlidge, A., Hanna, A., Rudd, C., Macfarlane, I., Windebank, J., Rance, S.: An introductory overview of ITIL V3 (2007)

28. Böttcher, M., Klingner, S.: Providing a method for composing modular B2B services. J. Bus. Ind. Mark. 26(5), 320-331 (2011)

29. Kohlborn, T., Fielt, E., Korthaus, A., Rosemann, M.: Towards a service portfolio management framework. In: Proceedings of 20th Australasian Conference on Information Systems, pp. 112 (2009)

30. Ralyté, J., Rolland, C.: An assembly process model for method engineering. In: Dittrich, K.R., Geppert, A., Norrie, M.C. (eds.) CAiSE 2001. LNCS, vol. 2068, pp. 267-283. Springer, Heidelberg (2001). https://doi.org/10.1007/3-540-45341-5_18

31. Kohlborn, T., Korthaus, A., Chan, T., Rosemann, M.: Identification and analysis of business and software services-a consolidated approach. IEEE Trans. Serv. Comput. 2(1), 50-64 (2009)

32. Andersson, B., Johannesson, P., Zdravkovic, J.: Aligning goals and services through goal and business modelling. Inf. Syst. E-bus. Manag. 7(2), 143-169 (2009)

33. Ramel, S., Grandry, E., Dubois, E.: Towards a design method supporting the alignment between business and services software. In: Proceedings - International Computer Software and Applications Conference, vol. 1, pp. 349-354 (2009)

34. Lo, A., Yu, E.: From business models to service-oriented design: a reference catalog approach. In: Parent, C., Schewe, K.D., Storey, V.C., Thalheim, B. (eds.) ER 2007, vol. 4801, pp. 87-101. Springer, Heidelberg (2007). https://doi.org/10.1007/978-3-540-75563-0_8 
35. Grandry, E., Dubois, E., Picard, M., Rifaut, A.: Managing the alignment between business and software services requirements from a capability model perspective. In: Mähönen, P., Pohl, K., Priol, T. (eds.) ServiceWave 2008. LNCS, vol. 5377, pp. 171-182. Springer, Heidelberg (2008). https://doi.org/10.1007/978-3-540-89897-9_15

36. Bianchini, D., Cappiello, C., De Antonellis, V., Pernici, B.: P2S: a methodology to enable interorganizational process design through web services. In: van Eck, P., Gordijn, J., Wieringa, R. (eds.) CAiSE 2009. LNCS, vol. 5565. LNCS, pp. 334-348. Springer, Heidelberg (2009). https://doi.org/10.1007/978-3-642-02144-2_28

37. Jamshidi, P., Sharifi, M., Mansour, S.: To establish enterprise service model from enterprise business model. In: Proceedings of 2008 IEEE International Conference on Services Computing, SCC 2008, vol. 1, pp. 93-100 (2008)

38. Kaabi, R.S., Souveyet, C., Rolland, C.: Eliciting service composition in a goal driven manner. In: Proceedings of the 2nd International Conference on Service Oriented Computing - ICSOC 2004, p. 308 (2004)

39. Kim, Y., Doh, K.: The service modeling process based on use case refactoring. In: Abramowicz, W. (eds.) BIS 2007. LNCS, vol. 4439, pp. 108-120. Springer, Heidelberg (2007). https:// doi.org/10.1007/978-3-540-72035-5_9

40. Klose, K., Knackstedt, R., Beverungen, D.: Identification of services - a stakeholder-based approach to SOA development and its application in the area of production planning. In: ECIS, no. 2007, pp. 1802-1814 (2007)

41. Kohlmann, F., Alt, R.: Business-driven service modeling - a methodological approach from the finance industry. In: Sabre 2007, pp. 1-14 (2007)

42. Lee, J., Muthig, D., Naab, M.: An approach for developing service oriented product lines. In: 2008 12th International Software Product Line Conference, pp. 275-284 (2008)

43. Lee, J., Sugumaran, V., Park, S., Sansi, D.: An approach for service identification using value co-creation and IT convergence. In: Proceedings of 1st ACIS/JNU International Conference on Computers, Networks, Systems, and Industrial Engineering, CNSI 2011, pp. 441-446 (2011)

44. Suntae, K., Minseong, K., Sooyong, P.: Service identification using goal and scenario in service oriented architecture. Neonatal. Paediatr. Child Heal. Nurs. 419-426 (2008)

45. Si, H., Ni, Y., Yu, L., Chen, Z.: A service-oriented analysis and modeling using use case approach. In: Proceedings of 2009 International Conference Computational Intelligent Software Engineering, CiSE 2009, no. 60773163 (2009)

46. Wang, Z., Xu, X., Zhan, D.: Normal forms and normalized design method for business service. In: IEEE International Conference on e-Business Engineering (ICEBE 2005), pp. 79-86 (2005)

47. Yu, E.: Modelling strategic relationships for process reengineering (1995)

48. Offerman, T., Stettina, C.J., Plaat, A.: Business capabilities: a systematic literature review and a research agenda. In: 2017 International Conference on Engineering, Technology and Innovation (ICE/ITMC) (2017)

49. Michell, V.: A Focused Approach to Business Capability, no. Bmsd, pp. 105-113 (2013)

50. Grefen, P., Turetken, O., Traganos, K., den Hollander, A., Eshuis, R.: Creating agility in traffic management by collaborative service-dominant business engineering. In: CamarinhaMatos, L., Bénaben, F., Picard, W. (eds.) PRO-VE 2015, IFIP Advances in Information and Communication Technology, vol. 463, pp. 100-109. Springer, Heidelberg (2015). https://doi. org/10.1007/978-3-319-24141-8_9

51. Peffers, K., Rothenberger, M., Tuunanen, T., Vaezi, R.: Design science research evaluation. In: Design Science Research in Information Systems. Advances in Theory and Practice, pp. 398-410 (2012) 